\title{
Classification of avian haemolytic Actinobacillus-like organisms (Bisgaard taxon 26) associated with anseriforme birds as Actinobacillus anseriformium sp. nov.
}

\author{
M. Bisgaard and H. Christensen
}

Correspondence

H. Christensen

hech@life.ku.dk

\author{
Department of Veterinary Disease Biology, Faculty of Life Sciences, University of Copenhagen, \\ 4 Stigbøjlen, DK-1870 Frederiksberg C, Denmark
}

Christensen \& Bisgaard (2010) briefly reviewed the molecular classification of selected members of the Pasteurellaceae

The GenBank/EMBL/DDBJ accession numbers for the partial rpoB sequences of strains $F 66^{\top}$ and 20834/6 are HQ257237 and HQ257238, respectively, and for the partial recN sequences of strains $\mathrm{F}_{6}{ }^{\top}$ and $\mathrm{F} 64$ are HQ257239 and HQ257240, respectively.

Two supplementary figures and two supplementary tables are available with the online version of this paper. of veterinary importance and its impact on diagnostics and understanding the phylogeny and epidemiology of these taxa. These organisms are mainly to be found within the genera Actinobacillus, Avibacterium, Bibersteinia, Gallibacterium, Histophilus, Mannheimia and Pasteurella. However, several unclassified taxa of veterinary importance exist that remain to be classified. In addition, many taxa have been reported that impose major diagnostic problems (http://www.the-icsp. org/taxa/Pasteurellaceaelist.htm) (Christensen \& Bisgaard, 
2008). Avian haemolytic Actionobacillus sp. associated with the mucosa of the respiratory tract of apparently normal White Pekin ducks was first reported by Bisgaard (1982). DNA-DNA hybridizations between (-)-D-sorbitol-negative (F64; biovar 3) and -positive ( $\mathrm{F}{ }^{\mathrm{T}}$; biovar 1 ) isolates demonstrated $82 \%$ DNA binding. These isolates, however, only clustered with a (-)-D-mannitol-negative isolate (F97) with $65 \%$ DNA binding, whereas around $50 \%$ DNA binding was observed with the type strain of Actinobacillus ureae (Piechulla et al., 1985). Blindness from conjunctivitis in a Canada goose (Branta canadensis) caused by Actinobacillus suis was reported by Maddux et al. (1987). These bacteria have subsequently been shown to be phenotypically similar to avian haemolytic Actinobacillus-like organisms (M. Bisgaard, unpublished data), later tentatively named taxon 26 (Bisgaard, 1993). DNA-DNA hybridization results reported by Piechulla et al. (1985) and Mutters et al. (1989) located taxon 26 in the vicinity of Actinobacillus.

Subsequent studies on inter- and intrafamilial similarities of rRNA cistrons of the Pasteurellaceae placed taxon 26 (NCTC 11410; see Supplementary Table S1, available in IJSEM Online) at the common root of the rRNA branches for Pasteurella multocida, Actinobacillus lignieresii and Haemophilus influenzae (De Ley et al., 1990). The classification of the genus dates back to Brumpt (1910). Attempts have been made to reclassify Actinobacillus sensu stricto to include the type species A. lignieresii and the seven species Actinobacillus equuli, Actinobacillus capsulatus, A. suis, Actinobacillus pleuropneumoniae, Actinobacillus hominis, A. ureae and Actinobacillus arthritidis, whereas the eight species [Actinobacillus] seminis, [Actinobacillus] rossii, [Actinobacillus] minor, [Actinobacillus] indolicus, [Actinobacillus] porcinus, [Actinobacillus] delphinicola, [Actinobacillus] scotiae and [Actinobacillus] succinogenes need reclassification (Christensen \& Bisgaard, 2008). This proposal has mainly been based on phylogenetic 16S rRNA gene sequence comparisons, DNA-DNA reassociation data, phylogenetic comparisons of additional conserved gene sequences and phenotypic data (Christensen et al., 2007). A. capsulatus was found to be polyphyletic with Actinobacillus sensu stricto by $16 \mathrm{~S}$ rRNA gene sequence comparison, whereas all other data pointed to classification with Actinobacillus sensu stricto (Kuhnert et al., 2007).

According to Busse et al. (1997), polyamine patterns are useful for discrimination within the family Pasteurellaceae. Members of the genus Actinobacillus sensu stricto have been characterized by the presence of 1,3-diaminopropane as the predominant compound, which makes up some $90 \%$ of the total polyamines of taxon 26 (MCCM $01376=F 64)$ and thus corresponds well with the type strain of A. lignieresii, the type species of the genus Actinobacillus. However, [Pasteurella] langaaensis demonstrated a polyamine pattern close to taxon 26 (Busse et al., 1997) (square brackets around genus names indicate species that possibly should be excluded from the genera Pasteurella, Actinobacillus or Haemophilus, in accordance with the terminology of Mutters et al., 1989). Comparison of 16S rRNA gene sequences between strains $\mathrm{F}^{\mathrm{T}}{ }^{\mathrm{T}}$ (biovar 1) and F97 (biovar 2) demonstrated $99.8 \%$ similarity, whereas the similarity to strain F64 (biovar 3) was 99.6\% (Christensen et al., 2003). A single isolate, 20948/1, obtained from sinusitis in a goose, demonstrated $99.8 \% 16 \mathrm{~S}$ rRNA gene sequence similarity to $\mathrm{F} 66^{\mathrm{T}}$ and represents a $\mathrm{V}$-factor-dependent isolate of taxon 26 (Christensen et al., 2009). Maximum-likelihood analysis of $16 \mathrm{~S}$ rRNA gene sequences of taxa of Pasteurellaceae included taxon 26 with the monophyletic group of Actinobacillus sensu stricto (Christensen et al., 2003; Christensen \& Bisgaard, 2004). Delineation of the genus Actinobacillus by comparison of partial infB sequences showed that [Pasteurella] pneumotropica $\mathrm{P} 421^{\mathrm{T}}$ and taxa 26 (CCUG 28015) and 8 (P1572) of Bisgaard were more remotely related with core species of Actinobacillus and should not be classified with Actinobacillus sensu stricto if an $85 \%$ similarity demarcation line is used for delineation of Actinobacillus sensu stricto (Nørskov-Lauritsen et al., 2004).

A new and simplified procedure to identify species of Actinobacillus, Avibacterium, Gallibacterium, Haemophilus, Mannheimia, Nicoletella and Pasteurella, which are most commonly isolated from clinical samples of diseased animals in veterinary diagnostic laboratories, was presented recently (Dousse et al., 2008). The procedure enabled identification of 240 out of 267 field isolates investigated. According to this method, taxon 26 would be classified with Actinobacillus equuli subsp. haemolyticus, undermining our present understanding of the biology and significance of taxa of Pasteurellaceae. For the same reasons, the aims of the present investigation were to further characterize, classify and name organisms tentatively named taxon 26 .

A total of 65 strains were included in the investigation, including all biovars of taxon 26 that have been characterized phenotypically according to Bisgaard et al. (1991) and Christensen et al. (2007) as reported previously (Christensen et al., 2003, 2009). Out of the 65 strains, only 31 isolates have been kept/survived and are available for genotypic characterization. The partial $r p o B$ sequences of all isolates investigated (Supplementary Table S1, available in IJSEM Online) were determined according to Mollet et al. (1997) covering the region 509-680 (Escherichia coli numbering) of the deduced protein sequence, as reported previously (Angen et al., 2003; Korczak et al., 2004). recN gene sequences were used as a representative target for determining whole-genome sequence similarity as described by Kuhnert \& Korczak (2006), with 1283 bp of the gene being sequenced in three strains. Whole genome similarity values were calculated according to Zeigler (2003).

A BLAST search (Altschul et al., 1997) was performed in GenBank (Benson et al., 2010). Pairwise comparisons of similarity were performed by the program WATER included in EMBOSs (Rice et al., 2000). Multiple alignments were performed with CLUSTAL_X (Thompson et al., 1997). Sequences in multiple alignments were trimmed to the same length in BioEdit (Hall, 1999) by removal of all columns with gaps in the $5^{\prime}$ and $3^{\prime}$ ends of sequences. Phylogenetic trees were drawn from MEGA4 (Tamura et al., 
2007). Maximum-likelihood analysis including bootstrap analysis was performed by fastDNAml (Felsenstein, 1995; Olsen et al., 1994) on a Linux-compatible server. The analysis was run with transition/transversion ratios of 2.6 and 2.3 for $r p o B$ and $\operatorname{recN}$, respectively.

The phenotypic results available for the 65 isolates from anserine birds have all been reported previously (Bisgaard, 1982; Christensen et al., 2003, 2009). Forty-nine isolates belonged to biovar 1, whereas 11 isolates belonged to biovar 2 and three belonged to biovar 3 . In addition, one V-factorrequiring strain was included that was originally published by Christensen et al. (2009). Two isolates originally classified with taxon 26 (biovars 3 and 4) could not be confirmed by genotypic analysis and were excluded from the investigation. Results reported are in accordance with those reported for Actinobacillus sensu stricto (Christensen \& Bisgaard, 2004; Olsen \& Møller, 2005; Kuhnert et al., 2007). Characters separating taxon 26 from other species of Actinobacillus sensu stricto are in Table 1. Five to 12 characters separate taxon 26 from other taxa of Actinobacillus, with A. ureae demonstrating the closest relationship; taxon 26 can be differentiated from $A$. ureae based on differences in haemolysis, $\beta$-glucosidase and acid production from (-)D-sorbitol, trehalose and glycosides. Twelve characters separate taxon 26 and the V-factor-requiring strain from A. lignieresii (Table 1).

Twenty-nine strains representing biovars 1 to 3 had the same $r p o B$ sequence as a representative strain $\left(\mathrm{F}^{3} 6^{\mathrm{T}}\right.$; biovar 1). Strain $20834 / 6$ diverged in $1 \mathrm{nt}$ ( $99.6 \%$ similarity). Highest $r p o B$ similarity outside the group of strains investigated $(89.7 \%)$ was obtained with the type strain of A. equuli subsp. haemolyticus, whereas the similarity to the type strain of A. lignieresii was slightly lower (88.2\%). Phylogenetic analysis of taxon 26 and type and reference strains of Actinobacillus showed that it was a distantly related member of Actinobacillus sensu stricto. The apparent relationship with [A.] minor was unsupported by bootstrap analysis (Supplementary Fig. S1, available in IJSEM Online) and not confirmed by $16 \mathrm{~S}$ rRNA or $\operatorname{recN}$ phylogenetic analysis (see below). One reason for this could be that only a partial region was analysed. The $r p o B$ sequence-based phylogeny was included to evaluate the genotypic coherence of strains of taxon 26 studied and not to investigate phylogenetic relationships at the genus level.

Christensen \& Bisgaard (2004) reanalysed sequences with a minimum length of $1346 \mathrm{nt}$ from 83 strains representing 58 named and 25 unnamed taxa of the Pasteurellaceae which contained fewer than 10 ambiguous bases and showed that taxon 26 should be classified with Actinobacillus sensu stricto. $16 \mathrm{~S}$ rRNA gene sequence similarities of strains representing biovars 1-3 were 99.6-99.8\% (Christensen et al., 2003, 2009) indicating that taxon 26 seems to represent a single species. 16S rRNA gene sequence similarities between taxon 26 and the type strains of named taxa of Actinobacillus sensu stricto, genomospecies 1 and 2, and Bisgaard taxon 8 varied between $93.9 \%$ (A. capsulatus) and $96.4 \%$ (Actinobacillus genomospecies 2) with $95.3-95.8 \%$ similarity to the type strain of A. lignieresii, indicating that DNA-DNA reassociation experiments are not mandatory for establishing and naming taxon 26 as a novel species of Actinobacillus (Tindall et al., 2010).

recN similarities within taxon 26 varied from $99.5 \%\left(\mathrm{~F}^{2} 6^{\mathrm{T}}\right.$ and F64) to $99.8 \%$ (F66 ${ }^{\mathrm{T}}$ and F67), corresponding to genome similarities of 93.9-94.6\%, which is clearly at the upper limit for species compared to other members of the Pasteurellaceae (Christensen et al., 2011; Kuhnert \& Korczak, 2006). The highest recN similarity outside taxon $26(83.4 \%)$ was observed with the type strain of A. capsulatus, whereas similarity to the type strain of A. lignieresii was $80.9 \%$ corresponding to genome similarities of $57.7 \%$ and $52.0 \%$, respectively, for $A$. capsulatus and A. lignieresii, clearly confirming the distant relationship of taxon 26 to other species of Actinobacillus. Phylogenetic analysis of recN gene sequences of taxon 26 and type and reference strains of Actinobacillus gave similar results to the $16 \mathrm{~S}$ rRNA analysis in Fig. 1, in that it was the most distantly related member of Actinobacillus sensu stricto, with [A.] minor being the most closely related outgroup (Supplementary Fig. S2, available in IJSEM Online). The 16S rRNA gene sequence phylogeny shown on Fig. 1, including Actinobacillus sensu stricto, and [A.] minor and Mannheimia haemolytica as outgroup, documented monophyly of the isolates studied with Actinobacillus sensu stricto, including A. lignieresii. Multiple alignments and phylogenetic trees were constructed as described above for $r p o B$ - and recN-derived phylogenies. In the current $16 \mathrm{~S}$ rRNA gene sequence-based phylogeny, a transition/transversion ratio of 1.1 optimized the multiple likelihood.

DNA-DNA hybridizations between F66 ${ }^{\mathrm{T}}$ (biovar 1) and F64 (biovar 3) demonstrated $82 \%$ DNA binding according to Piechulla et al. (1985). Strain F64 only clustered at $65 \%$ DNA binding with biovar 2 (F97). Considering the standard deviation of $7.3 \%$ stated in the paper, the usual threshold of $70 \%$ DNA reassociation seems to be included with the estimate. Only $51 \%$ DNA binding was observed between F66 ${ }^{\mathrm{T}}$ and F97. These results clearly suggest that biovar 2 represents a separate species, contradicting $r p o B$, inf $B$ and $16 \mathrm{~S}$ rRNA gene results. However, DNA-DNA hybridizations have previously generated conflicting results as discussed by Kuhnert \& Korczak (2006), Christensen et al. (2007) and Bisgaard et al. (2009). Based upon the work of Zeigler (2003), Kuhnert \& Korczak (2006) proposed that sequence comparison of recN might replace DNA-DNA hybridization experiments.

Based on previous investigations of phenotypic characteristics and $16 \mathrm{~S}$ rRNA analysis, as well as $r p o B$ and $r e c N$ gene sequence comparisons presented in this investigation, a novel species, Actinobacillus anseriformium sp. nov., is proposed to accommodate Bisgaard taxon 26. Previously published $16 \mathrm{~S}$ rRNA gene sequence phylogenies (Christensen et al., 2003; Christensen \& Bisgaard, 2004; Olsen et al., 2005) all documented that taxon 26 was a member of Actinobacillus sensu stricto. 
Table 1. Phenotypic characters separating Actinobacillus anseriformium from other taxa of Actinobacillus sensu stricto

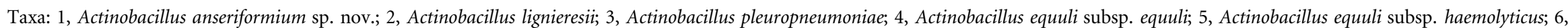

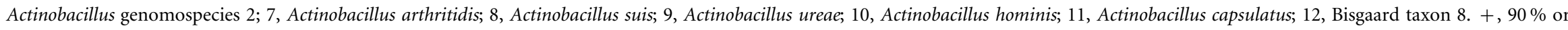

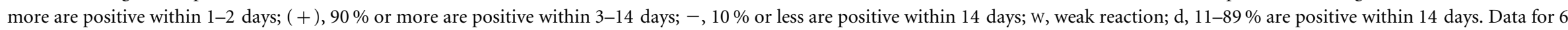

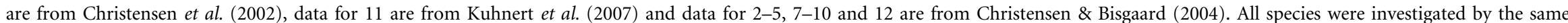
methods and under the same cultural conditions.

\begin{tabular}{|c|c|c|c|c|c|c|c|c|c|c|c|c|}
\hline Characteristic & 1 & 2 & 3 & 4 & 5 & 6 & 7 & 8 & 9 & 10 & 11 & 12 \\
\hline Symbiotic growth & - & - & $\mathrm{d}^{*}$ & - & - & - & - & - & - & - & - & - \\
\hline$\beta$-Haemolysis & + & - & + & - & $+/ \mathrm{w}$ & - & - & + & - & - & - & - \\
\hline Pigment & - & - & - & - & - & - & - & $\mathrm{w}$ & - & - & - & - \\
\hline \multicolumn{13}{|l|}{ Acid from: } \\
\hline$(+)$-L-Arabinose & - & - & - & $\mathrm{d}$ & - & - & $\mathrm{d}$ & + & - & - & $\mathrm{d}$ & - \\
\hline (-)-D-Arabinose & - & $+/(+)$ & $\mathrm{d}$ & - & - & $\mathrm{d}$ & $\mathrm{d}$ & - & - & - & - & - \\
\hline (+)-D-Xylose & - & + & + & + & + & + & + & + & - & + & + & + \\
\hline (-)-D-Mannitol & $d^{*}$ & + & + & + & $\mathrm{d}^{*}$ & + & + & - & + & + & + & + \\
\hline (-)-D-Sorbitol & $+^{*}$ & - & - & - & - & - & $+/(+)$ & - & - & - & + & - \\
\hline$(-)$-L-Fucose & - & + & $(+)$ & - & - & d & d & - & - & - & - & - \\
\hline (+)-D-Galactose & - & + & + & + & + & $+/(+)$ & $+/(+)$ & + & - & + & $+/(+)$ & $(+)$ \\
\hline (+)-Melibiose & - & - & - & $+/(+)$ & + & $\mathrm{d}$ & $+/(+)$ & + & - & $+/(+)$ & $+/(+)$ & $(+)$ \\
\hline Trehalose & + & - & - & + & + & - & - & + & - & + & + & - \\
\hline Raffinose & - & $\mathrm{d}$ & $\mathrm{d}$ & + & + & + & + & + & - & + & + & + \\
\hline Inulin & - & - & - & - & - & - & - & - & - & + & - & - \\
\hline Other glycosides $\dagger$ & $+/(+)$ & - & - & - & $d^{*}$ & - & - & $+/(+)$ & - & $\mathrm{d}$ & + & - \\
\hline ONPG & - & + & + & + & + & + & + & + & - & + & + & + \\
\hline$\alpha$-Galactosidase & - & - & - & + & + & + & + & + & - & + & + & + \\
\hline $\begin{array}{l}\alpha \text {-Glucosidase ( } p \text {-nitrophenyl } \\
\alpha \text {-D-glucopyranoside) }\end{array}$ & $\mathrm{d}$ & - & - & $\mathrm{d}$ & $\mathrm{d}$ & - & - & + & - & $\mathrm{d}$ & $\mathrm{d}$ & - \\
\hline $\begin{array}{l}\beta \text {-Glucosidase ( } p \text {-nitrophenyl } \\
\beta \text {-D-glucopyranoside) }\end{array}$ & + & - & - & - & + & - & - & + & - & + & + & - \\
\hline $\begin{array}{l}\beta \text {-Xylosidase (2-nitrophenyl } \\
\beta \text {-D-xylopyranoside) }\end{array}$ & - & - & - & + & $\mathrm{d}$ & $\mathrm{d}$ & - & + & - & - & - & + \\
\hline Hosts & $\begin{array}{l}\text { Anseriforme } \\
\text { birds }\end{array}$ & $\begin{array}{l}\text { Cattle, sheep, } \\
\text { horses } \ddagger\end{array}$ & Pigs & Horses, pigs & Horses & Horses & Horses & Pigs & Humans & Humans & Leporidae & Guinea pigs \\
\hline
\end{tabular}

${ }^{\star}$ Biovars reported.

$\dagger$ Includes salicin, amygdalin, arbutin and gentiobiose.

$\ddagger$ Separate genomospecies 1 . 


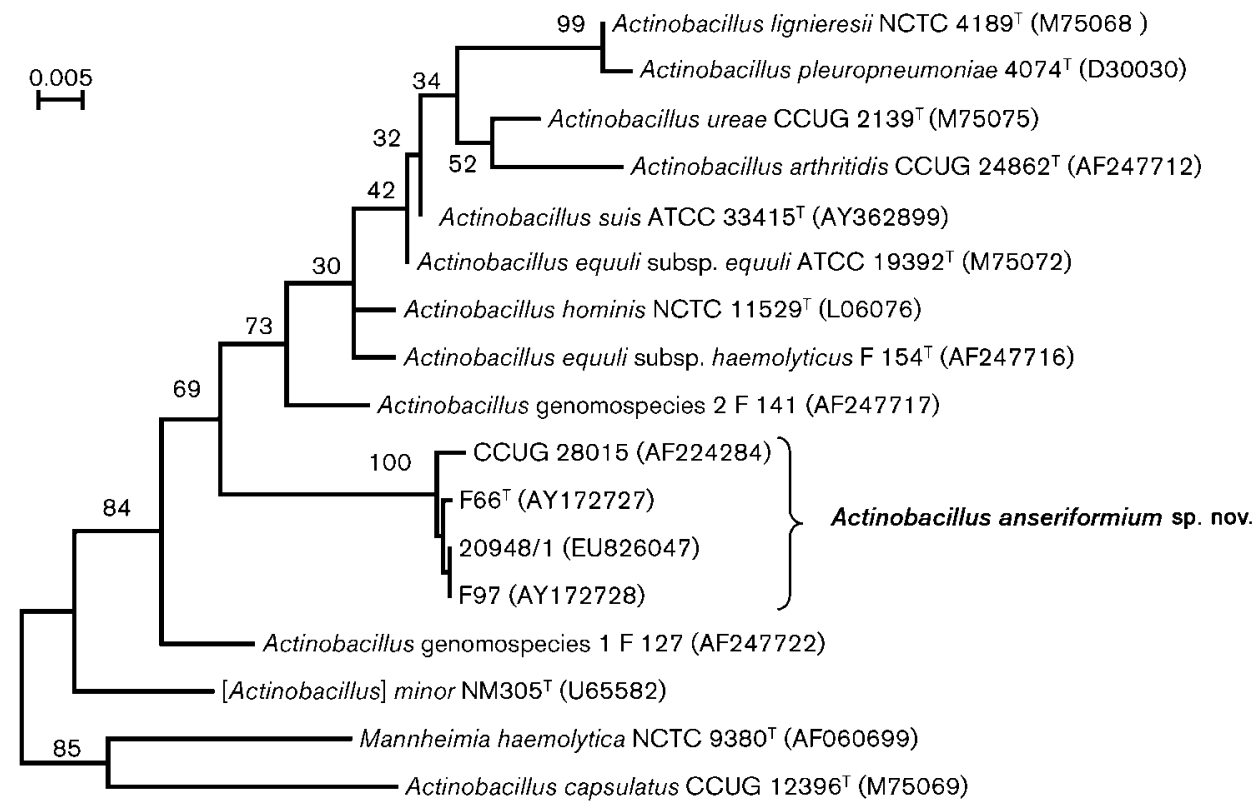

Fig. 1. Phylogenetic relationships between Actinobacillus anseriformium and existing members of Actinobacillus sensu stricto based on maximum-likelihood analysis of nearly full-length 16S rRNA gene sequences; strains of [A.] minor and Mannheimia haemolytica were used as the outgroup. Support values (\%) for monophyletic groups by bootstrap analysis are indicated. Accession numbers are given after strain numbers. Bar, sequence variation considering the models for nucleotide substitution and tree-shape used in the maximum-likelihood analysis.

Compared to rpoB- and recN-derived phylogenies, a minor difference observed in the $16 \mathrm{~S}$ rRNA phylogeny was that taxon 26 formed an in-group to Actinobacillus genomospecies 1 that was the most distantly related member of Actinobacillus sensu stricto with [A.] minor being the closest related outgroup (Fig. 1). This was also shown by Christensen et al. (2003). The unusual location of $A$. capsulatus was described and explained by Kuhnert et al. (2007). The type strain, $\mathrm{F}_{6}{ }^{\mathrm{T}}$, was selected from biovar 1 since this biovar is the most frequently reported. The fatty acid profile of the type strain was determined by the CCUG (Culture Collection, University of Göteborg, Göteborg, Sweden). Isolates were cultivated aerobically on Columbia II agar base (BBL 4397596) with $5 \%$ horse blood, for $16 \mathrm{~h}$ at $37^{\circ} \mathrm{C}$. Cells were carefully removed from the plate to avoid getting medium in the sample; 50-100 mg cells were further analysed according to Sasser (2001), Eerola \& Lehtonen (1988) and Viallard et al. (1998) as described in detail at http://www.ccug.se/pages/CFA_method_2008. pdf?CFID $=659629 \&$ CFTOKEN $=43544734$.

The main fatty acid was $\mathrm{C}_{16: 1} \omega 7 c$ with $\mathrm{C}_{14: 0}, \mathrm{C}_{16: 0}$ and $\mathrm{C}_{14: 0} 3-\mathrm{OH}$ and/or iso- $\mathrm{C}_{16: 1} \mathrm{I}$ as other major components (Supplementary Table S2, available in IJSEM Online). The profile corresponded well with that of the type strain of $A$. lignieresii, thus confirming the relationship of the novel species with the genus Actinobacillus. The DNA G+C content of strain F64 has previously been reported as $41.1 \mathrm{~mol} \%$ and the genome size is $2.0 \mathrm{GDa}$ (Piechulla et al., 1985). The DNA G + C content is very close to that of other members of Actinobacillus sensu stricto (Olsen et al., 2005).

There is an urgent need to reclassify the eight species [A.] seminis, [A.] rossii, [A.] minor, [A.] indolicus, [A.] porcinus, [A.] delphinicola, [A.] scotiae and [A.] succinogenes in either new genera or within existing genera of the Pasteurellaceae. This is an ongoing process that recently led to the description of a new genus, Aggregatibacter (Nørskov-Lauritsen \& Kilian, 2006).

\section{Description of Actinobacillus anseriformium sp. nov.}

Actinobacillus anseriformium (an.se.ri.for'mi.um. N.L. pl. n. Anseriformes scientific name of an order which encompasses ducks, geese, swans and other web-footed birds; N.L. gen. pl. n. anseriformium of/from Anseriformes).

Isolates on blood agar form smooth and shiny, regular, circular, greyish-white colonies demonstrating slight transparency at the periphery. $\beta$-Haemolysis of bovine blood is observed, just as adherence to the agar is often noticed. After $24 \mathrm{~h}$ aerobic incubation at $37^{\circ} \mathrm{C}$, colonies are $0.5-1.0 \mathrm{~mm}$, increasing in size to $1.5 \mathrm{~mm}$ after $48 \mathrm{~h}$ incubation. Isolates may demonstrate in vitro satellitic growth, referred to as $\mathrm{V}$ factor or NAD requirement. All isolates investigated are Gram-negative, small coccoid or pleomorphic rods, which are non-motile at 22 and $37{ }^{\circ} \mathrm{C}$, and fermentative in Hugh and Leifson's medium with glucose. Most isolates, including the type strain, are positive for catalase and oxidase. All 
isolates meet the phenotypic characters outlined for Actinobacillus (Olsen \& Møller, 2005). All isolates are positive for acid formation from $(+)$-D-mannose, cellobiose and other glycosides and trehalose, and $\beta$-glucosidase, whereas negative reactions are observed for acid formation from (+)-L-arabinose, (-)-D-arabinose, (+)-D-xylose, $(-)$-L-fucose, (+)-D-galactose, lactose, (+)-melibiose, raffinose and inulin. In addition, positive ONPG, $\alpha$ galactosidase and $\beta$-xylosidase reactions are observed. Different reactions have been observed for acid formation from (-)-D-mannitol and (-)-D-sorbitol as well as for the $\alpha$-glucosidase test; the two former reactions form the basis for the establishment of biovars. The type strain $\left(\mathrm{F} 66^{\mathrm{T}}\right)$ belongs to biovar 1 and is positive for (-)-D-mannitol, (-)$D$-sorbitol and $\alpha$-glucosidase. The major fatty acids are $\mathrm{C}_{16: 1} \omega 7 c, \mathrm{C}_{14: 0}, \mathrm{C}_{16: 0}$, and $\mathrm{C}_{14: 0} 3-\mathrm{OH}$ and/or iso- $\mathrm{C}_{16: 1} \mathrm{I}$ with $\mathrm{C}_{12: 0}, \mathrm{C}_{18: 2} \omega 6,9 c$ and/or ante- $\mathrm{C}_{18: 0}, \mathrm{C}_{18: 1} \omega 9 c$ and $\mathrm{C}_{18: 0}$ as minor components (Supplementary Table S2, available in IJSEM Online). Isolates have been obtained from the upper respiratory tract of web-footed birds in which they may cause sinusitis or conjunctivitis, and they may cause septicaemia.

The type strain is $\mathrm{F}_{6} 6^{\mathrm{T}}\left(=\right.$ CCUG $60324^{\mathrm{T}}=$ CCM $\left.7846^{\mathrm{T}}\right)$, isolated from conjunctivitis in a White Pekin duck.

\section{Acknowledgements}

Excellent technical assistance was contributed by the technicians Pia Mortensen and Katrine Madsen. Drs Edward Moore, Enevold Falsen and Ken Molin, Culture Collection, University of Göteborg, Sweden are kindly thanked for performing the fatty acid analysis. We would like to express our thanks to Professor Jean P. Euzéby, Ecole Nationale Veterinaire, Toulouse, France for help with the Latin name.

\section{References}

Altschul, S. F., Madden, T. L., Schäffer, A. A., Zhang, J., Zhang, Z., Miller, W. \& Lipman, D. J. (1997). Gapped BLAST and PSI-BLAST: a new generation of protein database search programs. Nucleic Acids Res 25, 3389-3402.

Angen, O., Ahrens, P., Kuhnert, P., Christensen, H. \& Mutters, R. (2003). Proposal of Histophilus somni gen. nov., sp. nov. for the three species incertae sedis 'Haemophilus somnus', 'Haemophilus agni' and 'Histophilus ovis'. Int J Syst Evol Microbiol 53, 1449-1456.

Benson, D. A., Karsch-Mizrachi, I., Lipman, D. J., Ostell, J. \& Sayers, E. W. (2010). GenBank. Nucleic Acids Res 38 (Database issue), D46D51.

Bisgaard, M. (1982). Isolation and characterization of some previously unreported taxa from poultry with phenotypical characters related to Actinobacillus- and Pasteurella species. Acta Pathol Microbiol Immunol Scand $[B]$ 90, 59-67.

Bisgaard, M. (1993). Ecology and significance of Pasteurellaceae in animals. Zentralbl Bakteriol 279, 7-26.

Bisgaard, M., Houghton, S. B., Mutters, R. \& Stenzel, A. (1991). Reclassification of German, British and Dutch isolates of so-called Pasteurella multocida obtained from pneumonic calf lungs. Vet Microbiol 26, 115-124.

Bisgaard, M., Korczak, B. M., Busse, H.-J., Kuhnert, P., Bojesen, A. M. \& Christensen, H. (2009). Classification of the taxon 2 and taxon 3 complex of Bisgaard within Gallibacterium and description of Gallibacterium melopsittaci sp. nov., Gallibacterium trehalosifermentans sp. nov. and Gallibacterium salpingitidis sp. nov. Int J Syst Evol Microbiol 59, 735-744.

Brumpt, E. (1910). Précis de Parasitologie. Paris: Masson et Cie.

Busse, H.-J., Bunka, S., Hensel, A. \& Lubitz, W. (1997). Discrimination of members of the family Pasteurellaceae based on polyamine patterns. Int J Syst Bacteriol 47, 698-708.

Christensen, H. \& Bisgaard, M. (2004). Revised definition of Actinobacillus sensu stricto isolated from animals. A review with special emphasis on diagnosis. Vet Microbiol 99, 13-30.

Christensen, H. \& Bisgaard, M. (2008). Taxonomy and biodiversity of members of Pasteurellaceae. In Pasteurellaceae: Biology, Genomics and Molecular Aspects, pp. 1-26. Edited by P. Kuhnert \& H. Christensen. Norfolk: Caister Academic Press.

Christensen, H. \& Bisgaard, M. (2010). Molecular classification and its impact on diagnostics and understanding the phylogeny and epidemiology of selected members of Pasteurellaceae of veterinary importance. Berl Munch Tierarztl Wochenschr 123, 20-30.

Christensen, H., Bisgaard, M., Angen, Ø. \& Olsen, J. E. (2002). Final classification of Bisgaard taxon 9 as Actinobacillus arthritidis sp. nov. and recognition of a novel genomospecies for equine strains of Actinobacillus lignieresii. Int J Syst Evol Microbiol 52, 1239-1246.

Christensen, H., Foster, G., Christensen, J. P., Pennycott, T., Olsen, J. E. \& Bisgaard, M. (2003). Phylogenetic analysis by $16 \mathrm{~S}$ rDNA gene sequence comparison of avian taxa of Bisgaard and characterization and description of two new taxa of Pasteurellaceae. J Appl Microbiol 95, 354-363.

Christensen, H., Kuhnert, P., Busse, H.-J., Frederiksen, W. C. \& Bisgaard, M. (2007). Proposed minimal standards for the description of genera, species and subspecies of the Pasteurellaceae. Int J Syst Evol Microbiol 57, 166-178.

Christensen, H., Blackall, P. J. \& Bisgaard, M. (2009). Phylogenetic relationships of unclassified, satellitic Pasteurellaceae obtained from different species of birds as demonstrated by $16 \mathrm{~S}$ rRNA gene sequence comparison. Res Microbiol 160, 315-321.

Christensen, H., Bojesen, A. M. \& Bisgaard, M. (2011). Mannheimia caviae sp. nov., isolated from epidemic conjunctivitis and otitis media in guinea pigs. Int J Syst Evol Microbiol 61, 1699-1704.

De Ley, J., Mannheim, W., Mutters, R., Piechulla, K., Tytgat, R., Segers, P., Bisgaard, M., Frederiksen, W., Hinz, K.-H. \& Vanhoucke, M. (1990). Inter- and intrafamilial similarities of rRNA cistrons of the Pasteurellaceae. Int J Syst Bacteriol 40, 126-137.

Dousse, F., Thomann, A., Brodard, I., Korczak, B. M., Schlatter, Y., Kuhnert, P., Miserez, R. \& Frey, J. (2008). Routine phenotypic identification of bacterial species of the family Pasteurellaceae isolated from animals. J Vet Diagn Invest 20, 716-724.

Eerola, E. \& Lehtonen, O. P. (1988). Optimal data processing procedure for automatic bacterial identification by gas-liquid chromatography of cellular fatty acids. J Clin Microbiol 26, 1745-1753.

Felsenstein, J. (1995). PHYLIP (phylogeny inference package) version 3.57c. Distributed by the author. Department of Genome Sciences, University of Washington, Seattle, USA.

Hall, T. A. (1999). BioEdit: a user-friendly biological sequence alignment editor and analysis program for Windows 95/98/NT. Nucleic Acids Symp Ser 41, 95-98.

Korczak, B., Christensen, H., Emler, S., Frey, J. \& Kuhnert, P. (2004). Phylogeny of the family Pasteurellaceae based on $r p o B$ sequences. Int $J$ Syst Evol Microbiol 54, 1393-1399.

Kuhnert, P. \& Korczak, B. M. (2006). Prediction of whole-genome DNA-DNA similarity, determination of $\mathrm{G}+\mathrm{C}$ content and phylogenetic 
analysis within the family Pasteurellaceae by multilocus sequence analysis (MLSA). Microbiology 152, 2537-2548.

Kuhnert, P., Korczak, B. M., Christensen, H. \& Bisgaard, M. (2007). Emended description of Actinobacillus capsulatus Arseculeratne 1962, $38^{\mathrm{AL}}$. Int J Syst Evol Microbiol 57, 625-632.

Maddux, R. L., Chengappa, M. M. \& McLaughlin, B. G. (1987). Isolation of Actinobacillus suis from a Canada goose (Branta canadensis). J Wildl Dis 23, 483-484.

Mollet, C., Drancourt, M. \& Raoult, D. (1997). rpoB sequence analysis as a novel basis for bacterial identification. Mol Microbiol 26, 10051011.

Mutters, R., Mannheim, W. \& Bisgaard, M. (1989). Taxonomy of the Group. In Pasteurella and Pasteurellosis, pp. 3-34. Edited by C. Adlam \& J. M. Rutter. London: Academic Press.

Nørskov-Lauritsen, N. \& Kilian, M. (2006). Reclassification of Actinobacillus actinomycetemcomitans, Haemophilus aphrophilus, Haemophilus paraphrophilus and Haemophilus segnis as Aggregatibacter actinomycetemcomitans gen. nov., comb. nov., Aggregatibacter aphrophilus comb. nov. and Aggregatibacter segnis comb. nov., and emended description of Aggregatibacter aphrophilus to include V factordependent and V factor-independent isolates. Int J Syst Evol Microbiol 56, 2135-2146.

Nerskov-Lauritsen, N., Christensen, H., Okkels, H., Kilian, M. \& Bruun, B. (2004). Delineation of the genus Actinobacillus by comparison of partial infB sequences. Int J Syst Evol Microbiol 54, 635-644.

Olsen, I. \& Møller, K. (2005). Genus Actinobacillus Brumpt 1910, $849^{\mathrm{AL}}$. In Bergey's Manual of Systematic Bacteriology, 2nd edn, pp. 866-883. Edited by D. J. Brenner, N. R. Krieg, J. T. Staley \& G. M. Garrity. New York: Springer.

Olsen, G. J., Matsuda, H., Hagstrom, R. \& Overbeek, R. (1994). fastDNAmL: a tool for construction of phylogenetic trees of DNA sequences using maximum likelihood. Comput Appl Biosci 10, 4148.

Olsen, I., Dewhirst, F. E., Paster, B. J. \& Busse, H.-J. (2005). Family Pasteurellaceae. In Bergey's Manual of Systematic Bacteriology, 2nd edn, pp. 851-862. Edited by D. J. Brenner, N. R. Krieg, J. T. Staley \& G. M. Garrity. New York: Springer.

Piechulla, K., Bisgaard, M., Gerlach, H. \& Mannheim, W. (1985). Taxonomy of some recently described avian Pasteurella/Actinobacilluslike organisms as indicated by deoxyribonucleic acid relatedness. Avian Pathol 14, 281-311.

Rice, P., Longden, I. \& Bleasby, A. (2000). EMBOss: the European Molecular Biology Open Software Suite. Trends Genet 16, 276-277.

Sasser, M. (2001). Identification of bacteria by gas chromatography of cellular fatty acids, MIDI Technical Note 101. Newark, DE: MIDI Inc.

Tamura, K., Dudley, J., Nei, M. \& Kumar, S. (2007). MEGA4: Molecular Evolutionary Genetics Analysis (MEGA) software version 4.0. Mol Biol Evol 24, 1596-1599.

Thompson, J. D., Gibson, T. J., Plewniak, F., Jeanmougin, F. \& Higgins, D. G. (1997). The CLUSTAL_X windows interface: flexible strategies for multiple sequence alignment aided by quality analysis tools. Nucleic Acids Res 25, 4876-4882.

Tindall, B. J., Rosselló-Móra, R., Busse, H.-J., Ludwig, W. \& Kämpfer, P. (2010). Notes on the characterization of prokaryote strains for taxonomic purposes. Int J Syst Evol Microbiol 60, 249-266.

Viallard, V., Poirier, I., Cournoyer, B., Haurat, J., Wiebkin, S., OphelKeller, K. \& Balandreau, J. (1998). Burkholderia graminis sp. nov., a rhizospheric Burkholderia species, and reassessment of [Pseudomonas] phenazinium, [Pseudomonas] pyrrocinia and [Pseudomonas] glathei as Burkholderia. Int J Syst Bacteriol 48, 549-563.

Zeigler, D. R. (2003). Gene sequences useful for predicting relatedness of whole genomes in bacteria. Int J Syst Evol Microbiol 53, 1893-1900. 